\title{
Uma nova espécie de Portanus Ball (Hemiptera, Cicadellidae) do Brasil ${ }^{1}$
}

\author{
Adenomar Neves de Carvalho ${ }^{2} \&$ Rodney Ramiro Cavichioli ${ }^{3,4}$
}

${ }^{1}$ Contribuição número 1473 do Departamento de Zoologia, Universidade Federal do Paraná.

${ }^{2}$ Bolsista CAPES/UFPR. Endereço eletrônico:adenomarc@yahoo.com.br

${ }^{3}$ Departamento de Zoologia, UFPR. Caixa Postal 19020, 81531-980 Curitiba-PR, Brasil. Endereço eletrônico:cavich@ufpr.br ${ }^{4}$ Bolsista CNPq.

\begin{abstract}
A new species of Portanus Ball (Hemiptera, Cicadellidae) from Brazil. A new species of Portanus Ball, 1932 is described from Rondônia and Mato Grosso, Brazil. A description of the female genitalia is included.

Keywords. Cicadellidae; Neotropical; new species; Portanus; Xestocephalinae.

Resumo. Uma nova espécie de Portanus Ball, 1932 é descrita a partir de material coletado nos Estados de Rondônia e Mato Grosso, Brasil. A genitália da fêmea também é descrita.

Palavras-Chave. Cicadellidae; espécie nova; Neotropical; Portanus; Xestocephalinae.
\end{abstract}

O gênero Portanus Ball, 1932 destaca-se entre os Xestocephalinae por constituir um grupo exclusivamente neotropical. Atualmente, este gênero está constituído por 49 espécies nominais (CARVALHO \& CAVICHIOLI 2003).

Ao estudar exemplares das coleções do Instituto Nacional de Pesquisas da Amazônia (INPA) e Padre Jesus Santiago Moure, Departamento de Zoologia da Universidade Federal do Paraná (DZUP), provenientes das regiões centro-oeste e norte do Brasil (compreendendo os Estados de Rondônia e Mato Grosso), foi descoberta uma nova espécie de Portanus descrita neste trabalho.

\section{Portanus sagittatus sp. nov.}

(Figs. 1-10)

Diagnose. Cabeça, em vista dorsal, marrom-clara com distinta mancha esbranquiçada em forma de seta entre os ocelos; pigóforo com processo em forma de garra no ângulo apical da margem ventral; edeago com um processo pré-apical na margem anterior, fendido desde o ápice à metade da largura da haste.

Comprimento (mm). Macho 4,4 - 4,6; fêmea 4,4 - 4,8.

Coloração. No geral, marrom-clara com diversas manchas esbranquiçadas no vértice e pronoto. Vértice com uma grande mancha vertical e esbranquiçada em forma de seta no ápice, entre os ocelos; região da margem anterior do vértice com duas manchas ovais. Escutelo branco com duas manchas marrom-escuras pequenas na porção mediana; ângulos basais marrom-escuros. Asas anteriores marrom-claras subhialinas, com veias marrom-escuras intercaladas por manchas brancas.

Cabeça, em vista dorsal, mais larga do que longa; vértice claramente angulado com a margem anterior arredondada; sutura epicranial alongada, cerca de $2 / 3$ do comprimento mediano do vértice (Fig. 1); antenas quase tão longas quanto o corpo.
Pronoto liso, convexo e tão largo quanto a cabeça; margem posterior retilínea. Escutelo liso, porém a porção apical é finamente pontuada (Fig. 1). Asas anteriores com venação evanescente; com três células ante-apicais fechadas; célula costal presente.

Pigóforo mais longo do que largo; com lobo lateral apicalmente truncado; processo em forma de garra no ângulo apical da margem ventral; macrocerdas esparsamente distribuídas na porção apical (Fig. 2). Placa subgenital retangular, bipartida ao longo do seu comprimento, com a porção apical estreitada e voltada para cima; presença de uma linha despigmentada transversa no terço basal; macrocerdas robustas e unisseriadas, acompanhadas por cerdas longas e delgadas (Fig. 3). Conetivo em forma de Y com os braços muito durtos em relação à haste, com um processo lamelar na confluência ventral dos braços (Fig. 4). Estilos subcilíndricos e sinuosos; ápices bífidos, o ramo interno é muito delgado, agudo e perpendicular ao ramo externo (Fig. 4). Edeago, em vista lateral, longo e robusto; haste alargada com o ápice truncado e voltado para cima; com dois pares de processos espiniformes na margem lateral da haste: o par pré-apical é curto e agudo, porém o par da porção mediana apresenta-se alongado, agudo e voltado anteriormente; processo pré-apical na margem anterior da haste apresenta-se fendido desde o ápice até a metade da largura da haste; gonóporo apical (Fig. $5)$.

Fêmea semelhante ao macho. Pigóforo, em vista lateral, triangular, muito pronunciado posteriormente, com ápice agudo, recoberto por macrocerdas, sendo estas mais esparsas na margem dorsal (Fig. 6). Sétimo esternito pouco pronunciado posteriormente, seu comprimento na linha mediana corresponde a aproximadamente à metade da sua largura; margem posterior com uma concavidade mediana (Fig. 7). Oitavo esternito completamente membranoso. Valva I do ovipositor, em vista lateral, longa, com porção pré-apical 

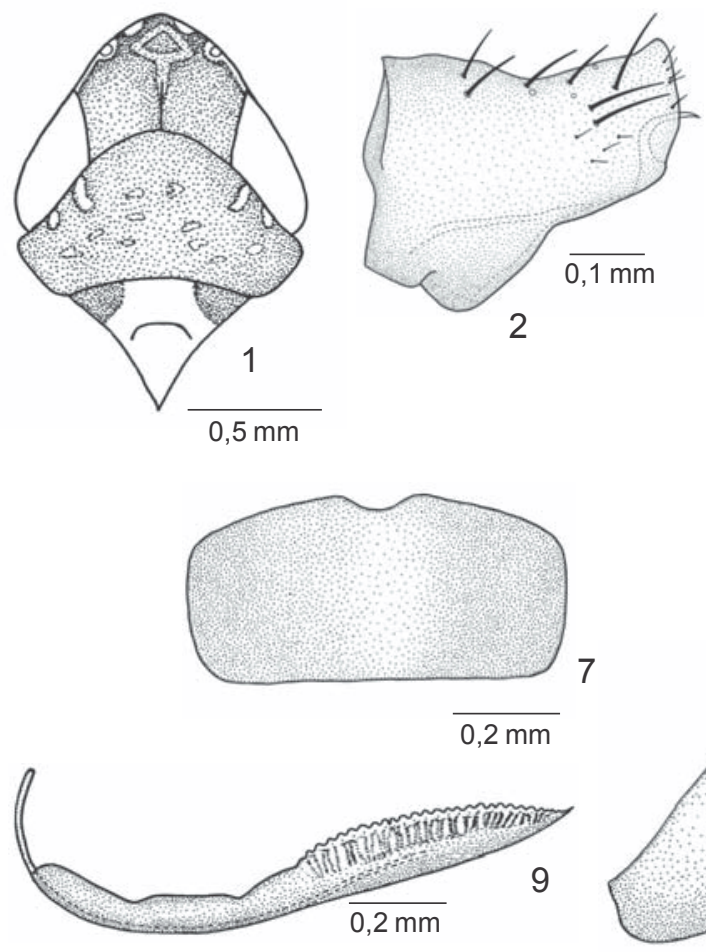

Figs. 1-10. Portanus sagittatus sp. nov. (Parátipo): 1, cabeça, pronoto e escutelo (vista dorsal); 2, pigóforo do macho (vista lateral); 3, placa subgenital (vista ventral); 4, estilo e conetivo (vista dorsal); 5, edeago (vista lateral); 6, pigóforo da fêmea (vista lateral); 7, sétimo esternito (vista lateral); 8, valva I do ovipositor (vista lateral); 9, valva II do ovipositor (vista lateral); 10, valva III do ovipositor (vista lateral).

alargada, estreitando-se ligeiramente para o ápice, que é agudo. Microcerdas estão presentes ao longo de todo o comprimento da valva, sendo mais numerosas na porção basal. Área esculturada dorsal estendendo-se do ápice à curvatura basal; processos tegumentares formados por estruturas escamiformes que se organizam em linhas oblíquas. Área esculturada ventral limitada à porção apical da valva; processos tegumentares formados por estruturas escamiformes dispostas irregularmente (Fig. 8). Valva II, em vista lateral, longa, expandida na porção apical, estreitando-se ligeiramente para o ápice, que é agudo. A superfície dorsal é ornada por aproximadamente 23 dentes com as margens laterais levemente convergentes apicalmente, sem dentículos na margem posterior; com diversos ductos estendendo-se para o ápice e base dos dentes e se abrindo em poros (Fig. 9). Gonoplaca ou valva III, em vista lateral, longa, com ápice agudo; metade basal distintamente mais estreita que a apical; porção apical com um pequeno número de cerdas e diminutas estruturas espiniformes, que se estendem para a base ao longo da margem ventral (Fig. 10).

Holótipo macho. BRASIL. Rondônia: Ouro Preto d'Oeste, 22.IX.1987, C. Elias leg (DZUP). Parátipos: ibdem, 1 fêmea, 27.X.1987, 1 macho, 22.IX.1987, 2 machos, 07.X.1987, 1 macho, 03.IX.1987, 1 macho, 18.II.1987 (DZUP). Rondônia: Nova Mamoré
(Parque Estadual de Guajará-Mirim, Rio Formoso), 1 macho e 1 fêmea, 27.X.1995, J. Vidal \& L. S. Aquino leg (INPA). Mato Grosso: Cáceres, 1 macho, XI.1984, 1 macho, 28.I.1985, C. Elias leg (DZUP).

Discussão. Portanus sagittatus sp. nov. compartilha com P. hasemani (Baker, 1923) a forma truncada do ápice do pigóforo do macho, um processo em forma de garra no ângulo apical da margem ventral (Fig. 2) e o ramo interno dos estilos muito delgado, agudo e perpendicular ao ramo externo (Fig. 4). Diferencia-se de P. hasemani, principalmente, pela forma do edeago e pela presença de dois pares de processos espiniformes na margem lateral da haste, o primeiro par préapical, curto e agudo, o segundo par na porção mediana, alongado e fortemente agudo.

Etimologia. (Latim: sagitta = seta). Refere-se à mancha esbranquiçada no ápice do vértice, entre os ocelos.

\section{REFERÊNCIA}

Carvalho, A. N. \& R. R. Cavichioli. 2003. Portanus Ball: descrições de dez espécies novas (Hemiptera, Cicadellidae, Xestocephalinae). Revista Brasileira de Entomologia 47(4): 547-558. 